\title{
БИОРЕМЕДИАЦИЯ НЕФТЯНЫХ ЗАГРЯЗНЕНИЙ В ВОДАХ КАСПИЯ
}

Кахраманова Кенуль Рамиз кызы

НАН Азербайджана «Институт химии присадок»

Аннотация: Нефть и нефтепродукты представляют собой наиболее опасные загрязнители водного бассейна. Ежегодно в моря и океаны попадает большое количество нефти, которое в виде нефтяной пленки плавает на поверхности воды, растворяется в ее толще и оседает на дно. Влияние нефти и нефтепродуктов приводит к ухудшению физических свойств воды. Способы биологической очистки экосистем от разливов нефти, основанные на использовании ферментативной активности углеводородокисляющих микроорганизмов в настоящее время считаются наиболее эффективными и экологически безопасными. Проведены работы по селективному отбору углеводородокисляющих микроорганизмов из загрязненных вод береговой зоны Бакинской бухты. Выделены активные формы углеводородокисляющих микроорганизмов, утилизирующих загрязняющие морские воды. Определены некоторые физико-химические характеристики нативной нефти из данной скважины, а также образцов нефти, подверженных деградации в условиях модельного эксперимента.

Ключевые слова: биоремедиация, нефтезагрязнение, углеводородокисляющие микроорганизмы, микробиологическая очистка морской воды, деструкция углеводородов нефти.

\section{BIOREMEDIATION OF OIL-CONTAMINATED WATERS OF THE CASPIAN SEA}

\section{Gahramanova Konul Ramiz}

\begin{abstract}
Oil and oil products are the most dangerous pollutants of the water basin. Every year, a large amount of oil enters the seas and oceans, which floats in the form of an oil film on the surface of the water, dissolves in its thickness and settles to the bottom. The influence of oil and oil products leads to a deterioration in


the physical properties of water. Methods for biological cleaning of ecosystems from oil spills, based on the use of the enzymatic activity of hydrocarbon-oxidizing microorganisms, are currently considered the most effective and environmentally friendly. Work has been carried out on the selective selection of hydrocarbonoxidizing microorganisms from the polluted waters of the coastal zone of the Baku Bay. The active forms of hydrocarbon-oxidizing microorganisms that utilize polluting sea waters have been identified. Certain physicochemical characteristics of native oil from this well, as well as oil samples subject to degradation under the conditions of a model experiment, have been determined.

Key words: bioremediation, oil pollution, hydrocarbon-oxidizing microorganisms, microbiological purification of seawater, destruction of oil hydrocarbons

Интенсивное загрязнение территорий и акваторий нефтепродуктами требует разработки различных способов их очистки. На основе исследований по изучению способности природных экосистем к самоочищению разрабатываются биопрепараты для очистки объектов, загрязненных нефтью. Запланированная в рамках исследования деятельность по созданию биологического препарата для очистки морской воды от нефтяных загрязнений предусматривает использование высокопродуктивных углеводородокисляющих микроорганизмов. Самоочищение природных вод от загрязнения техногенными углеводородами происходит в результате физикохимических и биологических процессов, основную роль в которых играют микроорганизмы-деструкторы. Интенсивность микробиологического разрушения нефтепродуктов определяется их химическим составом, концентрацией, а также видовым разнообразием микроорганизмов и условиями их обитания [1,c.51-54].

В настоящее время одной из важнейших проблем Баку остается состояние Бакинской бухты. Акватория одной из самых удобных бухт Каспийского моря - Бакинской бухты находится в самом тяжелом экологическом положении. По мнению ученых-экологов дно бухты покрыто 7-метровым слоем донных отложений, что в свою очередь ведет к интенсивному выбросу в воду нефтяных углеводородов, в частности, метанола, вредного для здоровья людей. Большая концентрация вредных веществ привела к гибели рыб, моллюсков и водорослей, к снижению выработки кислорода. 
Нефтяные углеводороды отличаются от других загрязнителей тем, что являются природными органическими веществами, следовательно, имеют природные деструкторы - нефтеокисляющие микроорганизмы.

Микроорганизмы выполняют основное условие существования всего живого в биосфере, которое заключается в сбалансированном продуцировании и разложении органического вещества. Следует отметить, что скорость накопления загрязняющих веществ превышает проценты их деструкции как при самоочищении природных экосистем, так и в техногенных экосистемах. Это справедливо и для нефтяных углеводородов, загрязнение которыми природной среды все увеличивается в результате того, что в современном мире нефть стала одним из самых необходимых органических соединений для жизнедеятельности человечества [2, с.150].

Такое интенсивное загрязнение акваторий нефтепродуктами требует разработки различных способов их очистки. Наиболее эффективными считают созданные на основе природных углеводородокисляющих микроорганизмов биопрепараты для активизации процесса очищения от нефти [3, с.240].

Установлено, что микроорганизмы выступают в роли особых катализаторов разложения нефти. Практическое использование соответствующих микроорганизмов осуществляется путем внесения их в загрязненный объект в форме различных препаратов. Эффективность их воздействия во многом зависит от возможности создания условий, оптимальных для проявления активности. В природных экосистемах это не всегда достижимо, так как для них характерны существенные колебания физико-химических факторов. Тем не менее разработан целый ряд микробных препаратов на основе чистых и смешанных культур углеводородокисляющих микроорганизмов. Наряду с микробными клетками в препарат включают соединения, поддерживающие жизнедеятельность микроорганизмов в месте загрязнения. Следует отметить, что активность внесенных препаратов может подавляться аборигенными микробными популяциями, поэтому наиболее эффективными считают биопрепараты на основе природных углеводородокисляющих микроорганизмов различных таксономических и физиологических групп [4,c.1380-1381, 5,c.118].

Целью настоящей работы было исследование некоторых физикохимических и микробиологических характеристик образцов нефтезагрязненных вод, отобранных с прибрежной зоны Бакинской бухты, а 
также проведение работ по селективному отбору углеводородокисляющих морских микроорганизмов из загрязненных вод.

Проведено определение численности различных групп микроорганизмов: аэробных, анаэробных, азотфиксирующих и целлюлозоразлагающих, нитрифицирующих, денитрифицирующих, спорообразующих бактерий и актиномицетов, обитающих в морской воде (Таблица 1). Изученные штаммы могут быть использованы для создания биопрепаратов и их дальнейшего применения для биоремедиации нефтезагрязненных морских вод Бакинской Бухты.

Таблица 1

Количество микроорганизмов в нефтезагрязненной и чистой морской воде

\begin{tabular}{|l|c|c|}
\hline \multirow{2}{*}{ Микроорганизмы } & \multicolumn{2}{|c|}{ Количество микроорганизмов в морской воде (кл/мл) } \\
\cline { 2 - 3 } & $\begin{array}{c}\text { Нефтезагрязненная морская } \\
\text { вода }\end{array}$ & Чистая морская вода \\
\hline Бактерии & $54 \cdot 10^{5}$ & $78 \cdot 10^{7}$ \\
\hline Грибы & $52 \cdot 10^{2}$ & $23 \cdot 10^{3}$ \\
\hline Дрожжевые грибы & $38 \cdot 10^{2}$ & $45 \cdot 10^{3}$ \\
\hline Акциномицеты & $26 \cdot 10^{2}$ & $68 \cdot 10^{3}$ \\
\hline $\begin{array}{l}\text { Углеводород- } \\
\text { окисляющие бактерии }\end{array}$ & $64 \cdot 10^{5}$ & $23 \cdot 10^{3}$ \\
\hline Споровые & $11 \cdot 10^{3}$ & $72 \cdot 10^{4}$ \\
\hline $\begin{array}{l}\text { Аэробные } \\
\text { азотфиксирующие } \\
\text { бактерии }\end{array}$ & $20 \cdot 10^{3}$ & $32 \cdot 10^{2}$ \\
\hline $\begin{array}{l}\text { Анаэробные } \\
\text { азотфиксирующие } \\
\text { бактерии }\end{array}$ & $11 \cdot 10^{4}$ & $16 \cdot 10^{2}$ \\
\hline $\begin{array}{l}\text { Аэробные } \\
\text { зоразлагающие бактерии }\end{array}$ & $12 \cdot 10^{2}$ & $2 \cdot 10^{2}$ \\
\hline $\begin{array}{l}\text { Анаэробные целлюло- } \\
\text { зоразлагающие бактерии }\end{array}$ & $30 \cdot 10^{4}$ & $18 \cdot 10^{2}$ \\
\hline $\begin{array}{l}\text { Нитрифицирующие } \\
\text { бактерии }\end{array}$ & $15 \cdot 10^{2}$ & $6 \cdot 10^{2}$ \\
\hline $\begin{array}{l}\text { Денитрифицирующие } \\
\text { бактерии }\end{array}$ & $16 \cdot 10^{3}$ & \\
\hline
\end{tabular}

Общую численность мироорганизмов определяли методом предельных разведений и высевом соответствующего разведения $(0,05$ мл) на 
агаризованные среды: мясо-пептонный агар (МПА) для бактерий и сусло-агар (CA) - для грибов и дрожжей.

Для определения углеводородокисляющих бактерий были использованы среда Миллса, состава, (г/л): NaCl- 24,0; $\mathrm{MgSO}_{4} \times 7 \mathrm{H}_{2} \mathrm{O}-1,0$; KCl-0,7; $\mathrm{K}_{2} \mathrm{HPO}_{4}-2,0 ; \mathrm{Na}_{2} \mathrm{HPO}_{4}-3,0 ; \mathrm{NH}_{4} \mathrm{NO}_{3}-1,0 ;$ агар-агар-20 и среда Чапека, (г/л): сахароза - 30, $\mathrm{NaNO}_{3}-3, \mathrm{KH}_{2} \mathrm{PO}_{4}-1, \mathrm{MgSO}_{4} \times 7 \mathrm{H}_{2} \mathrm{O}-0,5, \mathrm{KCl}-0,5$, $\mathrm{FeSO}_{4} \times 7 \mathrm{H}_{2} \mathrm{O}$ - 0,01, агар-агар - 20 с использованием $1 \%$ сырой нефти. Для целлюлозоразлагающих бактерий среда Гетчинсона следующего состава: $\mathrm{KNO}_{3}-2,5 ; \quad \mathrm{K}_{2} \mathrm{HPO}_{4}-1,0 ; \quad \mathrm{MgSO}_{4} \times 7 \mathrm{H}_{2} \mathrm{O}-0,3 ; \quad \mathrm{CaCl}_{2}-0,1 ; \quad \mathrm{FeCl}_{3} \times 7 \mathrm{H}_{2} \mathrm{O}-0,01 ;$ $\mathrm{NaCl}-0,1$. Для нитрифицирующих бактерий была использована среда, состава(Г/л): $\left(\mathrm{NH}_{4}\right)_{2} \mathrm{SO}_{4}-2,0 ; \mathrm{K}_{2} \mathrm{HPO}_{4}-1,0 ; \quad \mathrm{MgSO}_{4}-0,5 ; \quad \mathrm{FeSO}_{4} \times 7 \mathrm{H}_{2} \mathrm{O} \quad-0,4 ;$ $\mathrm{NaCl}-0,4$. Культивацию микроорганизмов проводили в термостате при температуре $28-32{ }^{\circ} \mathrm{C}$ в течении 5-7, 7-14 дней соответственно для других микроорганизмов, культивирующихся в жидких питательных средах.

Микрофлора, в основном, представлена различными видами бактерий, актиномицеты, аэробные и анаэробные азотфиксаторы, аэробные и анаэробные целлюлозаразрушающие бактерии, грибы и др.

Для сравнительных анализов были определены некоторые физикохимические характеристики. Нами проведено фракционирование нефтей методом адсорбции и экстракции растворителями, значительно различающимися по полярности и растворяющей способности (Таблица 2). Элюирование проводили гексаном, бензолом, спирто-бензолом (1:1) и ацетоном. В качестве адсорбента использовали силикогель марки АСК и оксид алюминия.

Таблица 2

Физико-химическая характеристика нефти месторождения Биби-Эйбат

\begin{tabular}{|c|c|c|c|c|c|}
\hline \multirow[b]{2}{*}{ Образцы } & \multirow[b]{2}{*}{$\begin{array}{l}\text { Плотность, } \\
\Gamma / \mathrm{cm}^{3}\end{array}$} & \multicolumn{4}{|c|}{ Состав компонентов (фракции), \% (масс) } \\
\hline & & гексановая & бензольная & $\begin{array}{c}\text { спирто- } \\
\text { бензольная }\end{array}$ & ацетоновая \\
\hline Нефть (нативная) & 0,8440 & $\begin{array}{c}53 \\
n_{D}^{20} 1,4812\end{array}$ & $\begin{array}{c}15 \\
n_{D}^{20} 1,5075\end{array}$ & $\begin{array}{l}5 \\
-\end{array}$ & $\begin{array}{l}1 \\
-\end{array}$ \\
\hline $\begin{array}{l}\text { Нефть после } \\
\text { модельного } \\
\text { эксперимента }\end{array}$ & 0,8770 & $\begin{array}{c}49 \\
n_{D}^{20} 1,4876\end{array}$ & 38 & $\begin{array}{l}2 \\
-\end{array}$ & - \\
\hline
\end{tabular}


Методом ИК-спектроскопии проведен анализ фракций исследуемых нефтей. Исследование гексановых фракций нефти показало, что они бедны ароматическими структурами (поглощение $\mathrm{C}=\mathrm{C}$ в ароматических ядрах при $\left.1600 \mathrm{~cm}^{-1}\right)$. В спектрах присутствуют интенсивные полосы колебательных связей С-С в насыщенных (700-800, 1380, 2000-3000 см-1 ) структурах. Содержание метильных групп (изолированных и геминальных) определяли по интенсивности полос в области 1300-1400 $\mathrm{cm}^{-1}$.

В результате модельного эксперимента, проведенного в течение 25 дней плотность исследуемых нефтей несколько повысилась, количество гексановой фракции уменьшилось, а количество ароматической фракции увеличилось.

По ходу исследования нами также были проведены работы по селективному отбору углеводородокисляющих микроорганизмов из загрязненных вод береговой зоны Бакинской бухты. Создание эффективной ассоциации предполагает не только наличие активных штаммов деструкторов, но и изучение вопросов их совместимости в составе препарата, а также нахождение наиболее рациональной питательной среды и условий культивирования для них.

Степень деструкции нефти определяли весовым (гравиметрическим) методом по суммарному показателю убыли нефти в жидкой среде (Леоненко и др., 2010).
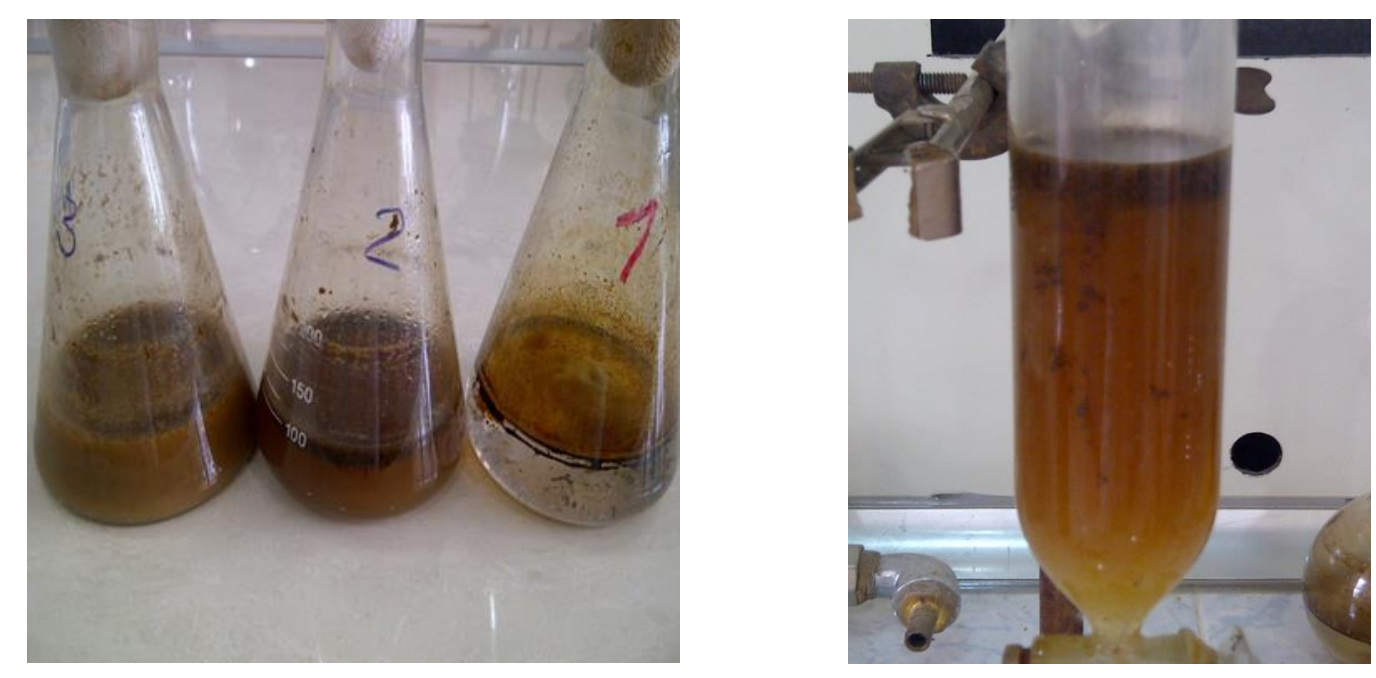

Рис. 1. Определение углеводородокисляющей способности микроорганизмов 
Экстракцию УВ проводили спустя 10 и 20 суток культивирования при $28-32^{\circ} \mathrm{C}$. В пробы для экстракции вносили по 20 мл эталонного н-гексана, после чего их помещали на орбитальный шейкер (220 об/мин) при температуре $25^{\circ} \mathrm{C}$ на 30 минут для перемешивания водной и углеводородной фазы и максимально полной экстракции компонентов нефти. [7, 75-76.] (Рис.1)

Таблица 3

Определение углеводородокисляющей активности бактерий, выделенных из нефтезагрязненной морской воды

\begin{tabular}{|c|c|c|c|c|}
\hline \multirow{2}{*}{$\begin{array}{c}\text { Углеводород- } \\
\text { окисляющие } \\
\text { культуры }\end{array}$} & \multicolumn{2}{|c|}{$\mathrm{pH}$} & \multirow{2}{*}{$\begin{array}{c}\text { Вес сухой } \\
\text { биомассы, } \\
\text { мг }\end{array}$} & \multirow{2}{*}{$\begin{array}{c}\text { Степень } \\
\text { деструкции } \\
\text { нефти, \% }\end{array}$} \\
\hline & до опыта & после опыта & & \\
\hline $1 \mathrm{~K}$ & 7,0 & 7,2 & 413 & 81 \\
\hline $2 \mathrm{~K}$ & 7,0 & 7,2 & 252 & 78 \\
\hline $3 \mathrm{~K}$ & 7,0 & 6,5 & 170 & 68 \\
\hline $4 \mathrm{~K}$ & 7,0 & 7,0 & 370 & 80 \\
\hline $5 \mathrm{~K}$ & 7,0 & 6.0 & 130 & 57 \\
\hline $6 \mathrm{~K}$ & 7,0 & 6,0 & 144 & 53 \\
\hline $7 \mathrm{~K}$ & 7,0 & 7,8 & 320 & 73 \\
\hline $8 \mathrm{~K}$ & 7,0 & 7,0 & 110 & 51 \\
\hline $9 \mathrm{~K}$ & 7,0 & 6,0 & 127 & 36 \\
\hline $10 \mathrm{~K}$ & 7,0 & 6,0 & 130 & 33 \\
\hline
\end{tabular}

Из данных (таблица 3) следует, что углеводородокисляющие микроорганизмы, выделенные из нефтезагрязненной воды прибрежной зоны Бакинской бухты очень эффективны. Данная композиция углеводородокисляющих микроорганизмов может быть рекомендована для разработки и использования нового препарата для биоремедиации нефтезагрязненных морских вод.

В результате исследований серии составов питательных сред отобраны наиболее рациональные из них для максимальной активизации микроорганизмов - деструкторов нефти, выделенных из морской воды различных территорий Бакинской бухты. С целью повышения углеводородокисляющей активности микроорганизмов и степени очистки вод 
найдены оптимальные условия культивирования для некоторых известных и новых аборигенных углеводородокисляющих микроорганизмов, выделенных из нефтезагрязненных вод прибрежной зоны Бакинской бухты.

В целях эффективного мониторинга загрязнения морской воды нефтеуглеводородами выделенные нами микроорганизмы в дальнейшем могут быть использованы в составе новых эффективных биопрепаратов, применяемых в процессах биоремедиации морских акваторий.

\section{Список литературы}

1. Демина Л.А. Как отмыть "Черное золото": О ликвидации нефтяных загрязнений // Энергия. - 2000. - N10. - С. 51-54.

2. Гольдберг В.М., Зверев В.П., Арбузов А.И., Казеннов С.М. и др. Техногенное загрязнение природных вод углеводородами и его экологические последствия. М: Недра, 2001 г., с.150

3. Дзержинская И.С., Курапов А.А. и др. Микроорганизмы в процессах деструкции и биоремедиации (проблемные лекции). АГТУ. НИИ проблем Каспийского моря. Астрахань: Издатель: Сорокин Р.В, 2009. с. 240

4. Wackett L.P. Biodegradation of fuel components/Environmental Microbiology, 2008, V.10, № 5, p.1380-1381.

5. Маркова М.Ю., Емельянова Л.Т. Новые технологии для очистки нефтезагрязненных вод, почв, переработки и утилизации нефтепродуктов. М.: Химия, 2001. 118c.

6. Гриднева В.В., Куликова И.Ю. Аборигенные углеводородокисляющие микроорганизмы в биоремедиации Северного Каспия от нефтяного загрязнения // Астраханский Государственный Технический Университет, Экология микроорганизмов, №4, 2010, С.79-86

7. Федоренко В.Н. Выделение и оценка биотехнологического потенциала микроорганизмов для утилизации нефтяных загрязнений северных морей : диссертация. - Москва - 2016, с.75-76

(С) К.Р. Кахраманова, 2021 